\title{
Geological factors of formation of radon containing water, Tskaltubo resort, Georgia
}

\author{
A. OKROSTSVARIDZE ${ }^{1 *}, \mathrm{~K}$ ACIMIDZE ${ }^{2}$, \\ D. BLUASHVILI ${ }^{3}$, S. GOGOLADZE ${ }^{1}$
}

${ }^{1}$ Institute of Earth Sciences, Ilia state University, Nutsubidze st 77, 0177 Tbilisi, Georgia

(*correspondence: okrostsvari@gmail.com)

${ }^{2}$ Tbilisi State University, Faculty Natural Sciences, 0179 Tbilisi, Georgia;

${ }^{3}$ Georgian Technical University, Faculty of Mining and Geology, 0160 Tbilisi, Georgia

Tskaltubo is a world-renowned balneological resort located in western Georgia. The main therapeutic feature of this resort is the unique radon containing springs, where the radon concentration varies between $40 \mathrm{~Bq} / \mathrm{m} 3$ and 100 $\mathrm{Bq} / \mathrm{m} 3$. The flow rate is $13-15$ million liters per day, the temperature varies from $+330 \mathrm{C}$ to $+350 \mathrm{C}$, that allows its use without preheating. General mineralization of spring water amount on average 0.7-0.8 g/l. Geological factors contributing to the water formation have been subject of discussion over a long period of time [1].

Tskaltubo is located in depression (80-120 $\mathrm{m}$ a.s.1.) and is surrounded by karstic Cretaceous limestones of 600-800 m high (Samgurali ridge). These formations are intruded by gabbroic dykes, part of which is outcropped in Tskaltubo depression and are highly expected to be the barriers along which the groundwaters find their way to the surface.

The Tskaltubo area has been studied by remote sensing (ASTER) and high concentrations of $U$ and Th have been revealed into the Samgurali ridge. Geological studies show, that the tectonic fault zones developed into the limestones are enriched in $U$ and $T h(U-200-300 \mathrm{~g} / \mathrm{t}$, Th $-250-400 \mathrm{~g} / \mathrm{t})$ [2].

To sum up, the formation of the radon containing Tskaltubo springs take place deep into the limestone bedrock, where it enrich in radon gas - $U$ and Th decay product. The preheating of spring waters (up to $+350 \mathrm{C}$ ) take place on the way they reach the surface because of the short half-life of $\mathrm{Rn} 222$ (3.8 days) ending at stable isotopes of lead ( $\mathrm{Pb} 206)$, when an important amount of heat energy release into the water.

[1] GAMA report (2015). [2] Natsvaladze et al. (1992). 